\title{
Discourse Markers in Hausa Proverbs: Exploring Intellectual Wise Saying from African Wisdom and Culture
}

\author{
Haruna Alkasim Kiyawa \\ Jigawa State College of Education, Gumel, Northern Nigeria \\ kiyawaharuna@gmail.com
}

\begin{abstract}
Received : 2020-10-04
Revised : 2021-02-17

Accepted : 2021-04-19
\end{abstract}

ARTICLE HISTORY

\section{KEYWORDS}

Proverbs

Hausa Proverbs

Discourse markers

Language use

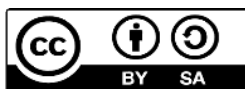

\begin{abstract}
This paper aims to explore some intellectual wise saying from African wisdom and culture from one of the three major languages in the northern part of Nigeria. The use of discourse markers is one of the linguistics devices embedded in Hausa proverbs. However, Africa as the continent was occupied by different languages and dialectics. Proverbs is an expression of a saying which combines various wisdom and culture of every human beings living on the earth. This paper utilises written document as a method and selected (36) different proverbs and analyses the discourse markers. Moreover, the paper reviewed various studies that looked at proverbs' role as one of a figurative speech and the definitions of discourse markers defined by literary scholars and cultural critics who studied proverbs from different perspectives. The finding of this paper identified (19) out of (36) proverbs also indicated DMs served as interpersonal functions and the relationship between the speakers' actions and thoughts, while the remaining (17) functions as textual features for making meaning. Finally, the study found that discourse markers enhance some lexical expressions under different levels, including sentence connectivity, language use, and the appearance of discourse markers in the proverbs. The study's significance shows that cultural scholars and English language educators can incorporate/integrate proverbs and highlighted the role of discourse markers to the student, enhancing their linguistics knowledge, communication skills and learning activities.
\end{abstract}

\section{Introduction}

Proverbs are one of the oral traditions that has been used for social contact and interaction among society and culture (Abubakar, 2015; Barasa, 2017). According to Mieder (2004), a prominent human philosopher who said that "proverbs belongs to wise saying and common knowledge in any language, indeed are a very effective mechanism to communicate wisdom and knowledge about human nature and world at large" (p.146). Based on this assertion, this present study focuses on exploring the usage of proverbs as of the oral customs of Hausa people in the northern part of Nigeria. In conveying, Hausa is a native language of some ethnic groups who call themselves Hausawa and are referred to as Hausa (s) in English. The majority of the Hausa people belong to a dominant ethnic group in an area known as the Hausa land in northern Nigeria, such as Kano, Katsina, Bauchi, Sokoto, Zaria Zamfara. Hausa people were believed to have settled in the northern Saharan regions of West African countries (Adisa, 2015; Chamo, 2011; Maimota, 2015). Hausa Proverbs are highly effective in exercising social control. They are used to maintain conformity to the accepted patterns of social behaviour, validate or justify social norms and apply social pressure, and exercise social control (Sarbi, 2013). Besides, the norm is meant a standard, for example, behaviour generally acceptable to society (Ibrahim, 2013; Ismail, 2013). This document is a version of the instructions for preparing copies for the final REiLA journal. The format here described allows for a graceful transition to the style required for that publication.

This paper's primary purpose is to describe the role of discourse markers that appeared in the Hausa language as one of the second major three languages after Swahili in Africa. Most available literature focuses mainly on English proverbs and others. However, this paper tried to uncover the role of proverbs as intellectual wise saying from African wisdom and culture, especially in northern Nigeria. There are limited studies that focus on the role of discourse markers in African proverbs, particularly in the Hausa language. For example, Jauro (et al., 2014) 
studied the influence of discourse markers in Nigerian newspapers. Other studies like Sadeghi \& Heidaryan (2012) investigated the effect of discourse markers in teaching EFL students listening comprehension in Iranian that discuses on English discourse markers. Their finding discussed the significance of discourse markers in the proverbs, which enhances the learners reading comprehension abilities. While (Yakubu 2013) also analyses the impact of discourse markers in academic report writing, it helped both teachers and their students in academic writing in the classroom context. Along these lines, Ibrahim (2013) clarifies some cultural material in the construction of Hausa proverbs and selected five different proverbs and explains its role of connotative and denotative meaning. The paper also revealed the significance of proverbs such as; teaching good manners, norms, codes, behaviours, and beliefs on how they shape the structure of the intellectual wise saying embedded in Hausa culture.

On the other hand, Gözpinar (2014) pointed the role of proverbs when incorporated in the curriculum of teaching different elements of culture, folklore, and multicultural varieties. These roles make it so difficult and challenging for teachers to familiar with their students as more critical ways of communicative devices, especially some foreign language teachers who have no idea of the significance of incorporating proverbs in their own culture or other culture of another target language. Finally, they concluded that proverbs help to enlighten both L1 and L2 on developing multicultural awareness among the teachers and their learners. From his part, (Hale, 1999) further explains the influence of discourse markers in Nigerian newspapers written in the English language, not Hausa proverbs. Furthermore, Alam and Al-Muthmainnah (2020) examined the wisdom, culture and language of an ethnic group, Soppeng people, one of Buginese, their characteristics of linguistic politeness devices, politeness strategies, and the realisation of local tradition found among Soppeng people one of the Buginese ethnic groups in Indonesia Their study utilised ethnolinguistics which originates from politeness theories, semiotics and pragmatics. Capture the Data were collected through purposive sampling and snowball among native speakers in Soppeng. The finding reveals that the realisation and the implication of local wisdom are primary values such as ethics and language politeness, self-image, courage, solidarity and cooperation.

Therefore, proverbs as a branch of oral tradition, its aesthetic values and cannot be overemphasised. This study is an effort to fill up the gap and explore to understand the practices of proverb use in the social and cultural life of the people from the African language. This study explores the function of discourse markers embedded in Hausa proverbs as wise saying from African wisdom and culture as cultural linguistics medium in the social and cultural life of the Hausa people. Hausa language, in which there is little knowledge on it, is considered a global language, unlike English proverbs.

Echoing from the above explanation, this paper's main objective is to explore intellectual wise saying from African Wisdom and culture and identify the discourse markers that appeared in Hausa proverbs and translate the Hausa proverbs into the English language. However, many studies have been conducted in the English language from different perspectives and applied different approaches. However, this paper employed descriptive content analysis to fill in the gap from one of the three major African languages after Swahili to add existing knowledge in oral literary scholarship.

\section{Literature Review}

Studies on an intellectual wise saying of culture and tradition, particularly proverbs, have received many scholars' attention regarding many social contexts across the globe. Several studies focused on proverbs and discourse markers concerning the English language from different contexts. For example, the linguistics aspect, teaching semantics aspect to enhance students' comprehension ability is mainly communicative competence. This triggered our interest to delve into the exploration of Hausa proverbs focusing on the appearance of discourse marker and its translation from Hausa into the English Language.

\subsection{Hausa Proverbs}

The Hausa term for proverb is "Karin Magana" Mieder (2004) "A proverb is a short, generally known sentence of the folk which contains wisdom, truth, morals and traditional views in a metaphorical, fixed and memorable form and which is handed down from generation to generation". Therefore, this present study sees "Proverbs are folk wisdom, which forms an essential part of the experience and way of life of the people who produce them". Furthermore, Piłaszewicz (1983, p.29) mentioned other typical features of Karin Magana: brevity, vagueness, and conciseness combined with the expressivity of their message, which is understandable in particular for the Hausa people. From his part, Obasanjo (2017) also highlighted that "Proverbs in most African languages are crisp, pithy and condensed means of saying much with few words" (Zajak, 2017, p.182).

Several studies are conducted in Hausa proverbs that cover a diverse area such as gender issues, cultural aspect, and linguistics pattern, to mention a 
few. For example, Yakubu (2020) examines gender position in Hausa proverbs and highlighted the class and position in African women's various ways. On the other hand, Ademowo and Nuhu (2017) studied Hausa proverbs' role in solving conflict management among ethnic groups in Nigeria. From his part, Sarbi (2013) discusses the Hausa proverb's role in teaching discipline to the younger generation.

\subsection{Definitions of Discourse Markers}

Discourse markers are said to instruct discourse participants how to consider an upcoming utterance, providing a pathway toward integrating different components of language use into one coherent discourse (Louwerse \& Mitchell, 2003, p.202). Moreover, Schifrin (2001) pointed out. They are syntactically heterogeneous. That is, they are comprised of members of word classes as varied as conjunctions (e.g. And, but, or), interjection (oh), adverbs (now, then) lexicalised phrases (Y, know, I mean) cited in (Walrod, 2006). Furthermore, Discourse markers were treated as "Fillers" or "expletive" words or phrases that had no function at all, while, now they are considered to function at different levels of analysis: topic changes, formulations discourse planning, stressing, hedging or channelling (Ghiad, 2009: 50) cited in (Ismail, 2012, p: 931). Besides, (Fraser 1999) "defined discourse markers as a class of lexical expressions drawn primarily from the syntactic classes of conjunctions, adverbs, and prepositional phrases.". Besides, a review of literature on similar area revealed the works on Hausa proverbs and as well as discourse markers, Therefore, from Hausa proverbs such as (Abdulkarim \& Abdullahi, 2015; Ademowo \& Nuhu, 2017; Adugna, 2014; Aminu, 2003; Ibrahim, 2013; Ismail, 2013; Ismail, 2012; Saleh, 2014; Usman, 2013). Unfortunately, none of these studies focused on the use of discourse markers in Hausa proverbs. In his study, Ibrahim (2013) observed some cultural material in Hausa proverbs' construction were selected five different proverbs and discussed their role connotative and denotative meaning. The paper also mentioned some advantages: good manners, religion, norms, codes, behaviours, and beliefs on how they shape the structure of the Hausa cultures.

Similarly, Ademowo \& Nuhu (2017) investigated the role of proverbs as a place of indigenous knowledge and peacebuilding in conflict management among Hausa speaking people of Northern Nigeria as a case study. The researchers randomly selected (20) different Hausa proverbs using discourse analysis to explain traditional knowledge as valuable tools in maintaining peace and peaceful co-existence among the people. It was concluded that Hausa proverbs served connectivity of disseminating meaning and ideas to solve the problem of conflict and further revealed its embedded literal meanings.

Unlike Ismail (2013), analysed some assimilation in the Hausa proverbs, which include; (i) palatalisation, (ii) velarisation, (iii) labialisation (iv) voicing. The studies selected (15) different Hausa proverbs and discussed in their various syllables of each proverb with (6- 20) different syllables were categorised and explained. Also, the study describes the statistical summary of the selected proverbs. The nasalisation appears (41) times, velarisation (6) times voicing assimilation, it appears only (3) times as well as palatalisation, which appears (3) times. Finally, the study suggested exploring Hausa Proverbs from another linguistics viewpoint.

Further, in their study, Sadeghi and Heidaryan (2012) analysed discourse markers' effect in teaching EFL students listening comprehension in Iranian. 50 participants were selected from the undergraduate level of Payam- Noor University in Iran. The participants randomly divided into two groups, "experimental and control groups". AFiftyre-test treatment programme, research hypothesis was designed to test based on the content of an authentic conversation, tests were drowned from TOEFL listening test (Gallagher, 2006) 600 words contains macro- markers in the texts, after conducting the pretext, a total mark was analysed using students' interpretation and recognition of DMs used. The finding indicates that the introduction of DMs in the Iranian students of EFL has a significant impact on improving their listening skills more especially in teaching foreign language in the classrooms. More so, teaching DMs in the classroom enhances students' interpretations and comprehension in EFL classes.

In contrast, Yakubu (2013) analysed the use of discourse markers in academic report writing, the objectives of their study were to show the appearance of discourse markers in the student's final projects. Data was collected through a corpus of final year dissertations, focusing mainly on the introductory sections, literature review, the methodology sections, the results and summary sections of the selected dissertations. The finding indicates that some discourse markers appeared in the introductory section, such as, also, despite, instead, but. Besides, it shows that discourse markers serve as a device that guides the reader in discourse. Recently, Yakubu et al. (2020) examine some selected wise saying concerning Hausa culture and traditions which put women as inferior subjects under the African patriarchal treatments. The study applied a feminist approach for the analysis. The finding reveals that both men and women need to be transformed into these traditional notions against women. Finally, it was suggested that women must have equal rights and privileges with 
their men counterpart for peace, harmony, prosperity, and development, despite the apparent advantages of using proverbs from the explanation above. However, this paper is in line with previous studies that revealed the significance of proverbs towards developing human socio-cultural values and traditions.

\section{Method}

This descriptive research applied a content analysis approach. This study aimed to describe and shows the appearance of the discourse markers embedded. The present study randomly selected samples (36) different Hausa proverbs as intellectual wise saying of African wisdom and culture from previous research studies (Abubakar, 2015; Abdulkarim \& Abdullahi, 2015; Aminu, 2003; Ademowo, \& Nuhu, 2017). The Data were analysed using a descriptive content analysis proposed by
Neuendorf (2004) to helps analyse the selected proverbs.

\section{Findings}

The purpose of the study is to describes the occurrences of discourse markers that appeared in the proverbs. The following section shows the selected Hausa proverbs and their translation in the English language. The markers that appeared in Hausa have underlined three categories in which DMs were classified according to their appearance in proverbs. While the second category indicated their translation into the English language, the third category from the table describes their function, including textual functions in the (17) out of the total number of (36) as already discussed in the paper's method.

Table 4.1 Hausa Proverbs and Their Translation into English Language/Textual Features.

\begin{tabular}{|c|c|c|c|}
\hline No & Hausa Proverbs & English Translation & $\begin{array}{l}\text { Proverbs that describes } \\
\text { Textual Features }\end{array}$ \\
\hline 1 & A dade ana yi sai gaskiya & 'Only truth and honest endures a while.' & Textual Features \\
\hline 2 & $\begin{array}{l}\text { Ai ciki da gaskiya wuka ba ta iya huda } \\
\text { shi }\end{array}$ & $\begin{array}{l}\text { 'The stomach that contains truth cannot be pierced } \\
\text { evenly with a knife' }\end{array}$ & Textual Features \\
\hline 3 & Duniya a bita a sannu & 'World affairs should be followed with caution & Textual Features \\
\hline 4 & Da hannau gara mannau & 'Better a minute thing than none' & Textual Features \\
\hline 5 & Gaskiya tafi jaka & 'Truth is worth more than a bag of money' & Textual Features \\
\hline 6 & Gaskiya tafi kwabo & 'Truth is worth more than a penny' & Textual Features \\
\hline 7 & Gaskiya tafi dokin karfe karfi & 'Honesty is worth stronger than a steel horse' & Textual Features \\
\hline 8 & Karya fure take bata 'ya'ya & $\begin{array}{l}\text { 'A lie falsehood only blossoms, but bears no fruit, but } \\
\text { forever' }\end{array}$ & Textual Features \\
\hline 9 & Shimfidar fuska ta fi shinfidar tabarma & 'To spread face is better than to spread of the mat' & Textual Features \\
\hline 10 & Tsakuwa daya bata dabe & 'A single/one pebble does not make the floor' & Textual Features \\
\hline 11 & A bar kaza cikin gashinta & 'Do not pluck the chicken' & Textual Features \\
\hline 12 & Komai nisan jifa kasa zai fado & 'What goes up must come down' & Textual Features \\
\hline 13 & Ramin karya Kurarre ne & 'The hole of lie is shallow' & Textual Features \\
\hline 14 & Riga kafi yafi magani & 'Prevention is better than cure' & Textual Features \\
\hline 15 & Motsi yafi labewa & 'Moving surpasses lurking still' & Textual Features \\
\hline 16 & Zaman lafiya yafi zama dan sarki & 'It is better to live in peace than to be a prince' & Textual Features \\
\hline 17 & Da hannau gara mannau & 'Better a little thing than none' & Textual Features \\
\hline
\end{tabular}


The findings showed in table 4.1 categorized the Hausa proverbs, their translation into the English language, and their interpersonal functions. However, Brinton (1996) argues that pragmatic markets serve as a fundamental component of grammaticalisation and discourse function to coherently make written or spoken language.
This assertion is in line with this paper's objective, which selected (17) Hausa proverbs and analyses the appearance of discourse markers and their roles of interpersonal functions, which helped every human discourse and guided the pragmatic flow of different languages used.

Table 4.2 Hausa proverbs and Their Translation into English/their Interpersonal Functions.

\begin{tabular}{|c|c|c|c|}
\hline No & Hausa Proverbs & Translation into the English Language & Interpersonal Functions \\
\hline 1 & Abin da ka shuka shi zaka girba & 'What you sow is what you reap.' & Interpersonal Functions \\
\hline 2 & Idan baki yaci ido da kunya & 'When mouth eats the face is in shame' & Interpersonal Functions \\
\hline 3 & $\begin{array}{l}\text { In zaka gina ramin mugunta, gina shi } \\
\text { gajere }\end{array}$ & $\begin{array}{l}\text { 'When digging a treacherous trench, it better digs a } \\
\text { shallow for; you might fall victim into it' }\end{array}$ & Interpersonal Functions \\
\hline 4 & Kowa ya bi za'a bi shi & $\begin{array}{l}\text { 'Whosoever follows in loyalty will also be } \\
\text { followed' }\end{array}$ & Interpersonal Functions \\
\hline 5 & $\begin{array}{l}\text { Kowa ya daka rawar wani ya rasa } \\
\text { turmin daka tasa }\end{array}$ & $\begin{array}{l}\text { 'Whoever tries to imitate someone else dances } \\
\text { without possessing the quality/experience of doing } \\
\text { so, will end in adversity' }\end{array}$ & Interpersonal Functions \\
\hline 6 & Kowa ya samu rana sai ya yi shanya & $\begin{array}{l}\text { 'Whosoever gets an opportunity should utilise it } \\
\text { with caution' }\end{array}$ & Interpersonal Functions \\
\hline 7 & $\begin{array}{l}\text { Wanda bai yi Hakuri da wahala ba ya } \\
\text { yi na talauci }\end{array}$ & $\begin{array}{l}\text { 'Whoever does not endure in hard work would } \\
\text { inevitably do so in absolute poverty' }\end{array}$ & Interpersonal Functions \\
\hline 8 & Zuwa da wuri ya fi zuwa da wuri- wuri & $\begin{array}{l}\text { 'Arriving with a penny is better than to arrive very } \\
\text { early' }\end{array}$ & Interpersonal Functions \\
\hline 9 & Kowa ya yi hakuri zai samu riba & - & Interpersonal Functions \\
\hline 10 & Hannu daya baya dauka Jinka & 'One hand cannot lift a hut' & Interpersonal Functions \\
\hline 11 & Rashin sani yafi dare duhu & 'Lack of knowledge is darker than night' & Interpersonal Functions \\
\hline 12 & Sai an sha wuya akan sha dadi & 'Enjoyment comes after struggling' & Interpersonal Functions \\
\hline 13 & Kaso dan'uwanka kamar kanka & 'Love your neighbour like yourself' & Interpersonal Functions \\
\hline 14 & Iya ruwa fidda kai & 'The ability to swim is the preservation of life' & Interpersonal Functions \\
\hline 15 & Abokin barawo,barawo ne & 'The Friend of a thief is a thief' & Interpersonal Functions \\
\hline 16 & Sauri ya haifi nawa & 'Overzealous can lead retrogression' & Interpersonal Functions \\
\hline 17 & Rashin sani yafi dare duhu & 'Lack of knowledge is darker than night' & Interpersonal Functions \\
\hline 18 & Kowa ya yi nigari dan akansa & 'Whosoever does good is for oneself' & Interpersonal Functions \\
\hline 19 & $\begin{array}{l}\text { In zaka fadi, fadi gaskiya komai taka } \\
\text { jamaka ka biya }\end{array}$ & 'Whenever you intend to speak, tell the truth' & Interpersonal Functions \\
\hline
\end{tabular}

The findings from Table 4.2 categorised the Hausa proverbs, their translation into the English language and classification of interpersonal functions. Let us starts with a proverb (1) Abin da ka shuka shi zaka girba literary mean 'What you sow, is what you reap' this inform the reader to be cautious and careful about doing good deeds other, but if he/she plan to fight or attach innocent people to harm people at the end she/he might be the one will receive or fallen into the terrible situation because of harm to others. Similarly, the proverb (3) In zaka gina ramin mugunta, gina shi gajere, meaning 'When digging a treacherous trench, it better digs a shallow for, you might fall victim into it' This proverb tells us how to be careful and always someone is expected to be good to others, not to harm anyone at all cost for better leaving and peaceful co- 
exitance. In addition to that, proverb (12) Kowa ya yi nigari dan akansa meaning' Whosoever does good is for oneself'. Considering the meaning of this wise saying where Hausa people always use this proverb to train the young generation to world life is meaningful, both young boys and girls should think critically before deciding or measures not to engage themselves into trouble. In the same vein, another proverb (18) Kowa ya yi nigari dan akansa, translation: 'Whosoever does good is for oneself' However, according to Brinton (1996) argues that pragmatic markets serve as essential components of grammaticalisation and discourse functions to make written or spoken language coherently. This assertion is in line with this paper's objective, which selected (19) Hausa proverbs and analyses the appearance of discourse markers and their roles of interpersonal functions of discourse pragmatic flow of different languages used.

Table 4.3 Hausa Discourses Makers and their Translation into the English Language

\begin{tabular}{cll}
\hline Number & Hausa Discourse Markers & Translation into the English Language \\
\hline 1 & A dade ana yi..... & 'Endures a while.' \\
2 & Ai ciki da gaskiya... & 'The stomach that contains truth' \\
3 & Duniya a bita.... & 'World affairs should be followed' \\
4 & Da hannau gara... & 'Better a little thing' \\
5 & Gaskiya tafi....... & 'Truth is worth more than' \\
6 & Gaskiya tafi........ & Truth is worth more than' \\
7 & Gaskiya tafi doki..... & 'Honesty is worth stronger than' \\
8 & Karya fure take bata..... & 'A lie falsehood only blossoms, but bears no fruit' \\
9 & Shimfidar fuska ta fi..... & 'To spread face is better than' \\
10 & Tsakuwa daya bata..... & 'A single/one pebble does not make' \\
11 & A bar kaza...... & 'Do not pluck the chick' \\
12 & Komai nisan jifa....... & 'What goes up must' \\
13 & Gaskiya tafi... & 'Truth is' \\
14 & Ramin karya... & 'The hole of lie' \\
15 & Riga kafi.. & 'Prevention is better' \\
16 & Motsi yafi & 'Moving surpasses' \\
\hline
\end{tabular}

Table 4.3 shows the listed Hausa Discourse Markers Appeared in the Proverbs were underlined and their translation into English. It is also indicated based on their textual features, which transmitted culture, traditions, wise saying ideas and thought from one generation to another. In addition, proverbs serve as a powerful instrument for the transmission of human philosophy, cultural values, teaching social moral to both adult and young and enhancing the sensibility of individual and people around you and others. Furthermore, the table below carried the listed Hausa discourse makers and their translation into the English language to benefit non-native speakers of the
African language. However, the essence of displaying Hausa written discourse markers was extracted from the central proverbs is to make it clear for readers to know the categories and their functions to connect the ideas in the sentence structure. Furthermore, the table below carried the listed Hausa discourse makers and their translation into the English language to benefit non-native speakers of the African language. However, the essence of displaying Hausa written discourse markers was extracted from the central proverbs is to make it clear for readers to know the categories and their functions to connect the ideas in the sentence structure. 
Table 4.4. Hausa Discourse Markers and their Translation into the English Language

\begin{tabular}{cll}
\hline Number & \multicolumn{1}{c}{ Hausa Discourse Markers } & \multicolumn{1}{c}{ Translation into the English Language } \\
\hline 1 & Abin da ka shuka & 'What you sow' \\
2 & Idan baki yaci & 'When mouth eats' \\
3 & In zaka gina ramin mugunta & 'When digging a treacherous trench' \\
4 & Kowa ya yi nagari & 'Whosoever does good' \\
5 & Kowa ya bi & 'Whosoever follows in loyalty' \\
6 & Kowa ya daka rawar wani & 'Whoever tries to imitate someone else dances without possessing \\
7 & Kowa ya samu rana & or the quality experience of doing so' \\
8 & Wanda bai yi Hakuri da wahala ba & Whosoever gets an opportunity should utilise' \\
9 & Zuwa da wuri.. & 'Whoever does not endure in hard work' \\
10 & Kowa ya yi hakuri & 'Arriving with a penny' \\
11 & Hannu daya baya... & 'Anyone who is patient' \\
12 & Rashin sani... & 'One hand cannot lift' \\
13 & Sauri ya ... & 'Lack of knowledge is darker' \\
14 & Sai an sha wuya ... & 'Overzealous can lead' \\
15 & Kaso dan'uwanka & 'Enjoyment come' \\
16 & Iya ruwa... & Love your neighbour' \\
17 & Abokin barawo... & 'The ability to swim' \\
18 & Rashin sani yafi & 'The Friend of a thief' \\
19 & In zaka fadi, fadi gaskiya & 'Whenever you intend to speak, tell the truth' \\
\hline
\end{tabular}

Table 4.4 shows three categories in which DMs were classified according to their appearance in Hausa proverbs. In contrast, the second category reveals their translation into the English language from the table describes their function, including interpersonal features that have (19) out of the total number of (36) they were embedded and were used by the people during conversation. The findings are in line with the view of prominent linguist Walrod (2006), who explains that discourse structure helps the speaker manipulate the strength and influence of the contextual indicators, guiding the person to communicate effectively and persuasively.

The results of this study described the occurrences of 19 Hausa discourse markers in the above table, which highlighted their two functions, i.e., (i) textual features and (ii) interpersonal functions. It contributed to the field of literary discourse and content analysis from one of the three major African languages is in line with the view of Schiffrin (1987), who argues that discourse markers contributed towards building the local coherence, which is in conjunction constructed by speaker and listener in their discourse structure, context, meaning and actions during the interaction. They served to show how and what is being said are interconnected to what has already been express, either within a speaker's turn or across speakers' turns.

\section{Discussion}

The study shows the appearance of underlined discourse markers in written Hausa proverbs, which revealed the intellectual wise saying of African traditions and culture embedded the significance in developing cultural norms and values of the people, especially youth, to every society.

This paper selected grouped and some majority of codes that appeared in the Hausa selected discourse markers as code such as are: (i) Gaskiya literary means (honesty/truth), (ii) Zaman lafiya (peaceful coexistence), (iii) Hakuri (patience), (iv) Juriya (perseverance), (v) Biyayya (obedience), (vi) Mutunci (respectively), (viii) Kirki (virtuosity). For example, Proverb no (1) in table 4.1 (a). A dade ana yi sai gaskiya translation means: 'Only truth and honest endures a while' this proverb means Hausa people believe that truth is the peal of everything in life if one 
agreed and behave to strictly adhere practising the truth in every personal policy, social interaction with others he/she will never felt down throughout in life.

Similarly, proverbs that use Gaskiya 'honesty/truth' are: (2), Ai ciki da gaskiya wuka ba ta iya huda shi, translation mean: The stomach contains truth cannot be pierced evenly with a knife. This proverb revealed that anybody who honest and trustworthy at all times he/she will not fear an untrusty person or terrible attack and is ways ready to speak the truth no matter how the situation will retaliate or bounce back to him (5) Gaskiya tafi jaka 'Truth is worth more than a bag of money' (6), Gaskiya tafi kwabo, translation mean 'Truth is worth more than a penny'(7), Gaskiya tafi dokin karfe karfi, translation mean: Honesty is worth stronger than a steel horse' In zaka fadi, fadi gaskiya komai taka jamaka ka biya, translation, Whenever you intend to speak, tell the truth' 30 .

A similar proverb that guided the younger generation to be good is (18). Kowa ya yi nigari dan akansa, translation 'Whosoever does good is for oneself' Even though they revealed different issues concerning socio-cultural aspect and attributes of people lives experiences social interaction, but shows the significance of practising truthy in all activities of someone to be good, humble, kind and generous so that they will succeed in life.

In addition to that, Zaman lafiya (peaceful coexistence). For example, (16), Zaman lafiya yafi zama dan sarki, translation means: 'It is better to live in peace than to be a prince', these proverbs tell us the nature of Africa royal system where king typically marries many wives (4), with at least has 20-30 children, then he has (10) extra concubines, and they have children with the king, so one of the children is competing and overzealous to become a king waiting for their father to die and is expecting to be selected by the kingmakers, this implies that to leave in peace is better than to be a prince. Juriya (perseverance), (3), Duniya a bita a sannu, translation 'World affairs should be followed with caution', this proverb implies that life is a matter of struggle, full of challenges, perseverance, and tolerance, so people must endure it no matter how it takes everything has an end so that joys and happiness will come.

Another proverb, (7) Wanda bai yi Hakuri da wahala ba ya yi na talauci, translation: 'Whoever does not endure in hard work would inevitably do so in absolute poverty'. This proverb encourages people to be patient and hardworking to get something doing instead of becoming lazy in the society he/she will become a jobless and hungry person (10), Kowa ya yi hakuri zai samu riba. Translation: 'Anyone who is patient will profit'. This proverb also entails the young people to a patient and courageous person in his life. In the end, he will succeed in life (12). Sai an sha wuya akan sha dadi, translation: Enjoyment comes after struggling' this proverb deployed to call the people's attention not to be lazy. One has to struggle hard and endure the situation or circumstances that may have encountered different bitter experiences at the end will succeed in life-Biyayya (obedience).

This code appeared in the selected proverbs that guided people to be obedient to parents, elders, and others in their day-to-day social interaction, which creates love and affection among them. Mutunci (respectively), This another code of the proverbs where the present paper utilised for easier understanding among the readers. For example, (5) Kowa ya bi za'a bi shi, translation: 'Whosoever follows in loyalty will also be followed', this proverb is calling to every individual to respect elders, parents and even the younger ones, he/she will expect such king a virtue and gesture to be respected by people in his/her community (15) Kaso dan'uwanka kamar kanka, translation: Love your neighbour like yourself', this proverb is counsel to every young people both male and female is expected to adopt cooperation and do away with selfishness and show love, caring, kindness and consideration to people as he/she loves himself /herself staying with or interacts elsewhere.

This study's findings revealed in table 4.1 (a) \& 4.1 found that all (36) Hausa proverbs contained discourse markers, and it was translated into the English language for easier understanding for nonnative Hausa language speakers. Furthermore, the findings in both four tables showed the Hausa discourse makers and their translation into the English language.

Therefore, there are (36) proverbs. The study found that (17) out of (36) indicated the DMs, which served as textual functions, while the remaining (19) also indicated DMs served as interpersonal functions and the relationship between the speakers' actions and thoughts. Based on this study's findings, the previous study of (Al-Yaari et al., 2013; Chapetón Castro \& Marcela, 2009), even though their study focuses on discourse markers' functions with students learning the English language in a classroom context.

The study argues that these proverbs provided insightful advice to the people who acted immorally to change to be good (Akinmade 2009; Gözpinar, 2014). Finally, they concluded that discourse markers play a significant in the connectivity and coherence in the construction of sentences.

A prominent human philosopher critic such According Schiffrin (1987) states that DMS discourse markers help the speaker manipulate the strength and 
influence of the contextual indicators, which guided the person to communicate effectively and persuasively. She further listed some signs of the discourse markers as follows while emphasising that these properties are interdependent and not one can be understood without attention to the others. i.e., (1). They form structure.; (2). They convey meaning and (3). They accomplish actions.

Finally, this assertion is in line with the present study. Therefore, Dms. It appeared in the proverbs it improves human critical thinking before taking any action or decisions in their social interaction with the society. In the selected Hausa proverbs, it was also indicated people to learn good things such as caution, morals, not to be lazy, arrogance, greed and ever advising individuals to be good in his/her/their lifespan (Esimaje \& Ezirim, 2014; Usman, 2013; Sarbi, 2013).

\section{Conclusion}

Researchers have widely studied DMs even if discussions on terminology and other linguistics issues are still unresolved. However, there seems to be a general understanding that the production of coherent discourse is functional activities that require speakers to draw upon communicative knowledge and cultural norms. It was discovered that most of the studies on DMs had focused their attention on English native speakers who acquire this pragmatic competence in their intermediate or adult learners in various classroom contexts. This is indicated that of the need to explore further and investigate the other African language apart from -native and non-English English learners, teachers' cultural linguistics research to know about intellectual wise saying outside their domain. One of my goals with this exploratory study was to describe the occurrences of DMs in African proverbs. The findings indicated discourse markers played a significant role in making sentence coherence and cohesion, which guided the reader to decode specific meaning and information from the proverbs analysed. Furthermore, the study's findings would help the language researchers, linguistic learners, cultural scholars, and Hausa language, especially those dealing with English and African proverbs as one of the intellectual wise sayings in the academic context. According to (Adugna, 2014; Saleh, 2014), it is essential to clear out that it was sometimes difficult to classify the DMs' function. Finally, this paper is limited to just appearance and translated the Hausa language written proverbs into the English language to benefit non-native speakers of the African language.

\section{Acknowledgement}

The author wishes to thank the Tet-fund management under the federal ministry of education Abuja, Nigeria, for sponsoring my PhD program in Applied Linguistics from Universiti Utara Malaysia (UUM), and I also thank the management of Jigawa State College of Education PM1002, Gumel, for the release of my study leave. Finally, I am happy and appreciate the editor, the reviewers, and the REiLA journal team for their kindness and support to publish my paper.

\section{References}

Abubakar, U. (2015). A Reflection of Hausa moral conduct in their proverbs. English studies international research journal, 3(1), 77-79.

Abdulkarim, Z., \& Abdullahi, H. (2015). Thematic analysis of some selected Hausa proverbs. Arts and design studies, 27, 27-30.

Ademowo, A. J., \& Nuhu, A. A. (2017). Indigenous knowledge and conflict management in Africa: A study of proverb use in conflict management among Hausas of Northern Nigeria. International Journal of History and Cultural Studies, 3(4), 3644.

Adisa, R. M., Mohammed, R., \& Ahmad, M. K. (2015). Newspaper framing of conflicts: Perceptions of ethnic group leaders on conflict behaviours in a multiethnic society. Malaysian Journal of Media Studies, 17(1), 29-44.

Adugna, A. B. (2014). Exploring Environmental Discourses in oral literature: Ecocritical analysis of Oromo proverbs. Journal of Languages and Culture, 5(2), 24-35.

Akinmade, C. A. (2009). Figures of association and sound in some Nigerian proverbs: Examples from Ondo culture. African research review, 3(3). 118132

Alam, F. A., \& Al-Muthmainnah, A. M. (2020). Exploring Local Wisdom in Buginese Ethnics: Language Politeness Phenomena of Tau Soppeng. REiLA: Journal of Research and Innovation in Language, 2(1), 14-18.

Al-Yaari, S. A. S., Al Hammadi, F. S., Alyami, S. A., \& Almaflehi, N. (2013). Using English discourse markers (EDMs) by Saudi EFL learners: A descriptive approach. International Journal of English Language Education, 1(2), 1-26.

Aminu, M. L. (2003). The Hausa Code of WorldLife: A Paremiological Exposition. In African Studies Association of Australasia and the Pacific 2003 Conference Proceedings-African on a Global Stage (pp. 1-21). 
Barasa, M. N., \& Opande, I. N. (2017). A sociocultural discourse representation of women in Bukusu and Gusii Proverbs.

Brinton, L. J. (2010). Pragmatic markers in English: Grammaticalisation and discourse functions (Vol. 19). Walter de Gruyter.

Chamo, I. Y. (2011). Language and identity: Hausa language of youth generation in Northern Nigeria. Studies in African Languages and Cultures, (45), 23-38.

Chapetón Castro, C. M. (2009). The use and functions of discourse markers in EFL classroom interaction. Profile Issues in Teachers Professional Development, (11), 57-78.

Esimaje, A. U., Masagbor, P. A., \& Ezirim, C. D. (2014). Unoka: The Gentleman Ill-at-Ease with the Code of Traditional Society: Exploration of the Proverbs of Four Nigerian Cultures.

Eslami, Z. R., \& Eslami-Rasekh, A. (2007). Discourse markers in academic lectures. Asian EFL Journal, 9(1), 22-38.

Fraser, B. (1999). What are discourse markers?. Journal of pragmatics, 31(7), 931-952.

Gözpinar, H. (2014). The Role of Proverbs in Forming Intercultural Awareness (On the Basis of Teaching English, Georgian and Turkish Languages). Online Submission.

Gözpinar, H. (2014). English Teachers' Interest in Proverbs in Language Teaching. Online Submission, 7(31), 611-617.

Hale, S. (1999). Interpreters' treatment of discourse markers in courtroom questions. Forensic Linguistics, 6(1), 57-82.

Hyuk, E. (2003). The effects of organisation markers on ESL learners' text understanding. TESOL quarterly, 37(4), 749-759.

Ismail, A. I. H. M. (2012). Discourse markers in political speeches: Forms and functions. Journal of the College of Education for Women, 23(4). 1260-1278

Jalilifar, A. (2008). Discourse Markers in Composition Writings: The Case of Iranian Learners of English as a Foreign Language. English Language Teaching, 1(2), 114-122.

Maimota Shehu, M. (2015). Clipping and blending in Hausa/Maryam Maimota Shehu (Doctoral dissertation, University of Malaya).
Mieder, W. (2004). Proverbs: A handbook. Greenwood Publishing Group.

Neuendorf, K. A. (2004). Content analysis: A contrast and complement to discourse analysis. Qualitative methods, 2(1), 33-36.

Newman, L. F. (1999). Introduction to Qualitative Research Methods: A Guidebook and Resource. The Journal of Nervous and Mental Disease, 187(9), 587.

Obasanjo, O. (2017). "Foreword". in: O. Okwelume. Drumbeats. The Proverbs of Africa. Lagos: Narrative Landscape Press

Piłaszewicz, S. (1983). Historia literatur afrykańskich w jezzykach rodzimych: literatura Hausa. Wydawnictwa Uniwersytetu Warszawskiego..

Sadeghi, B., \& Heidaryan, H. (2012). The effect of teaching pragmatic discourse markers on EFL learners' listening comprehension. English Linguistics Research, 1(2), 165-176.

Saleh, Y. S. (2014). A Contrastive Analysis of English and Hausa Proverbs in Selected Texts.

Sarbi, S., A. (2013). The Hausa proverbs as a tool for discipline. Paper presented at the international conference on folklore, national integration and development Bayero University Kano, Nigeria., $1-8$.

Schiffrin, D. (1987). Discourse markers (No. 5). Cambridge University Press.

Schiffrin, D. (2001). Discourse markers: Language, meaning, and context. The handbook of discourse analysis, 1, 54-75.

Usman, I. (2013). Cultural materials in the construction of Hausa proverbs. A paper presented at the international conference on folklore, national integration and development, in honour of professor Dandatti Abdulkadir, Bayero University Kano, 1-16.

Vanda, K. H., \& Péter, F. B. (2011). Gender differences in the use of the discourse markers you know and I mean. Argumentum, 7, 1-18.

Walrod, M. (2006). The marker is the message: The influence of discourse markers and particles on textual meaning. Philippine Journal of Linguistics, 37(2), 100-119.

Yakubu, M. S. (2013). An analysis of discourse markers in academic report writing: Pedagogical implications. International journal of academic and research and reflection, 1(3). 15-24. 
ISSN (Online): 2685-3906, ISSN (Print): 2685-0818

DOI: https://doi.org/10.31849/reila.5091

Vol. 3, No. 1, April 2021, pp. 42-51

Zając, P. (2018). Słowa-klucze kultury w przysłowiach hausa. Przeglad Orientalistyczny, 1(2) $155-181$. 